\title{
Impact of Airborne Pollutants on Stroke
}

\author{
Adeel Khoja, MBBS, MSc, ${ }^{1}$ Fizzah Kazim, MBBS $^{2}$ \\ ${ }^{1}$ The Aga Khan University, Karachi, Pakistan ${ }^{2}$ Dow University of Health Sciences, Karachi, Pakistan
}

\section{TO THE EDITOR}

The association of airborne pollutant exposure with cerebrovascular pathology is underrecognized. Air pollutants such as particulate matter have the potential to extend beyond pulmonary organs to the central nervous system. ${ }^{1}$ People living in highly polluted environments are at risk of developing neurodegenerative diseases, neurocognitive decline, and stroke. ${ }^{1}$ Stroke is one of the most common debilitating neurologic deficits. Each year, approximately 5 million people die from stroke, and it is a major cause of disability worldwide. ${ }^{2}$

Road traffic is one of the major contributors to outdoor air pollution and a major source of particulate matter, carbon monoxide, and nitrogen oxides. ${ }^{3-5}$ The level of nitrogen dioxide $\left(\mathrm{NO}_{2}\right)$ in the air is closely related to traffic-generated particles from car exhausts. ${ }^{3}$ Anderson et al showed a significant association between $\mathrm{NO}_{2}$ and stroke incidence: a $12 \%$ increase in the incidence of stroke and a 33\% increase in the incidence of fatal stroke. ${ }^{3}$ They concluded that reducing the level of $\mathrm{NO}_{2}$ might reduce the burden of stroke. ${ }^{3} \mathrm{~A}$ study conducted in England and Wales showed that men living in proximity to a major roadway had a $7 \%$ higher stroke mortality compared to those living far away. ${ }^{4}$

Air pollution is more strongly associated with ischemic stroke than hemorrhagic stroke. Exposure to particulate matter is associated with a $21 \%$ increase in hospital admissions for mild ischemic stroke ${ }^{5}$ and a $12 \%$ increase in hemorrhagic stroke admissions. ${ }^{6}$

Literature on cardiovascular disease has linked air pollution through systemic inflammation and endothelial damage to acceleration of atherosclerosis and thrombus formation. ${ }^{7}$ Loane et al highlighted that particulate matter and ultrafine particulate matter play a role similar to tobacco smoke in accelerating coronary arthrosclerosis that may lead to development of thrombotic stroke. ${ }^{1}$ The magnitude of personal risk due to air pollution is lower compared to other wellestablished risk factors; however, substantial population risk exists as almost everyone is exposed. ${ }^{5}$

The potential role of air pollution in the incidence of stroke and its adverse impact on health cannot be ignored. The stroke mortality rate continues to rise each year; moreover, millions of stroke survivors have serious, long-lasting disabilities. Air pollution is an important and modifiable risk factor for stroke, so public and environmental health policies aimed at curbing air pollution need to be implemented.

\section{REFERENCES}

1. Loane C, Pilinis C, Lekkas TD, Politis M. Ambient particulate matter and its potential neurological consequences. Rev Neurosci. 2013;24(3):323-335. doi: 10.1515/revneuro-2013-0001.

2. Lozano R, Naghavi M, Foreman K, et al. Global and regional mortality from 235 causes of death for 20 age groups in 1990 and 2010: a systematic analysis for the Global Burden of Disease Study 2010. Lancet. 2012 Dec 15;380(9859):2095-2128. doi: 10.1016/S0140-6736(12)61728-0.

3. Andersen ZJ, Kristiansen LC, Andersen KK, et al. Stroke and long-term exposure to outdoor air pollution from nitrogen dioxide: a cohort study. Stroke. 2012 Feb;43(2):320-325. doi: 10.1161/STROKEAHA.111.629246.

4. Maheswaran R, Elliott P. Stroke mortality associated with living near main roads in England and Wales: a geographical study. Stroke. 2003 Dec;34(12):2776-2780.

5. Andersen ZJ, Olsen TS, Andersen KK, Loft S, Ketzel M, Raaschou-Nielsen $\mathrm{O}$. Association between short-term exposure to ultrafine particles and hospital admissions for stroke in Copenhagen, Denmark. Eur Heart J. 2010 Aug;31(16):20342040. doi: 10.1093/eurheartj/ehq188.

6. Chiu HF, Chang CC, Yang CY. Relationship between hemorrhagic stroke hospitalization and exposure to fine particulate air pollution in Taipei, Taiwan. J Toxicol Environ Health A. 2014;77(19):1154-1163. doi: 10.1080/15287394.2014 .926801.

7. Brook RD, Rajagopalan S, Pope CA 3rd, et al; American Heart Association Council on Epidemiology and Prevention, Council on the Kidney in Cardiovascular Disease, and Council on Nutrition, Physical Activity and Metabolism. Particulate matter air pollution and cardiovascular disease: an update to the scientific statement from the American Heart Association. Circulation. 2010 Jun 1;121(21):2331-2378. doi: 10.1161/ CIR.0b013e3181dbece1. 